\title{
Anticuerpos contra Trichinella spiralis en la población rural de la provincia Cordillera, Bolivia
}

\author{
Alessandro Bartoloni, ${ }_{1}$ Gabriella Cancrini, ${ }^{2}$ Filippo Bartalesi, ${ }^{1}$ \\ Alessandra Nicoletti, ${ }^{3}$ Gerardo Méndez Prado, ${ }^{4}$ José Rosado, ${ }^{5}$ \\ Mimmo Roselli ${ }^{1}$ y Franco Paradisi ${ }^{1}$
}

RESUMEN Se realizó un estudio seroepidemiológico para determinar la prevalencia de anticuerpos contra Trichinella spiralis en el área rural de la provincia Cordillera del Departamento de Santa Cruz en Bolivia. Se examinaron 234 muestras de suero mediante el ensayo de inmunoabsorción enzimática (ELISA) y se detectaron los anticuerpos en siete muestras (3\%). Los resultados documentan por primera vez la presencia de infestación humana por Trichinella en Bolivia y sugieren la necesidad de fortalecer la vigilancia sanitaria de la triquinosis en los mataderos municipales, impedir la faena clandestina de animales y, sobre todo, lograr que los productores y pobladores tomen conciencia de los peligros de esta zoonosis.

La triquinosis es una zoonosis cuyo agente etiológico es un verme intestinal del género Trichinella. La enfermedad afecta a los animales salvajes y domésticos y puede ser transmitida al hombre por la ingestión de carne cruda o mal cocida de animales que contienen larvas infestadas viables, en particular carne de cerdo. La infección por Trichinella ha sido confirmada en 104 especies de mamíferos (1). En una revisión reciente de la taxonomía del gé-

\footnotetext{
1 Università di Firenze, Clinica di Malattie Infettive, Italia. Dirección postal: Via di Torregalli, 3, I 50143 Firenze, Italia. Correo electrónico: infdis@cesit1. unifi.it

2 Università "La Sapienza", Istituto di Parassitologia, Roma, Italia.

3 Università di Catania, Istituto di Scienze Neurologiche, Catania, Italia.

4 Laboratorio de Investigación y Diagnóstico Veterinario (LIDIVET), Santa Cruz, Bolivia.

5 Distrito de Salud de Cordillera, Departamento de Santa Cruz, Bolivia.
}

nero Trichinella, Pozio et al. (2) reconocen cinco especies (spiralis s.str., nativa, pseudospiralis, nelsoni s.str., britovi n.sp.) $\mathrm{y}$ tres fenotipos adicionales (T5, T6 y T8) cuyo nivel taxonómico aún no está definido. En la actualidad, la especie huésped no parece ser importante para distinguir las especies de Trichinella. Además, en la mayoría de los casos la variedad del reservorio animal refleja solamente la fauna presente en las distintas áreas geográficas.

La infección por el gusano triquina produce enfermedad en un porcentaje pequeño de los casos en humanos y se relaciona con la ingestión de una gran cantidad de larvas y con la patogenicidad de la cepa. La invasión de la pared intestinal -fundamentalmente del duodeno y el yeyuno- por los parásitos hembras origina una inflamación transitoria que puede producir diarrea y dolor abdominal semejantes a los asociados con muchas otras infecciones intestinales. La letalidad por triquinosis es menor de $1 \%$ y obedece a complicaciones secundarias graves ocasionadas por la localización encefálica, cardíaca o diafragmática de las larvas (3). La comprobación parasitológica puede realizarse mediante una biopsia muscular para detectar las larvas. El ensayo de inmunoabsorción enzimática (ELISA) es el mejor método actual de diagnóstico serológico disponible en el comercio (4): comparado con la biopsia, que es el patrón de oro, tiene una sensibilidad de $100 \%$ para detectar la inmunoglobulina G (IgG) específica contra antígenos de Trichinella spiralis (5) y una especificidad de alrededor de 97\% (6). Aunque se han realizado pocas investigaciones para confirmar su presencia en los países de América Latina, Asia y África, es probable que Trichinella esté diseminada 
en todo el mundo. En países como Chile y Argentina, donde ocurren periódicamente brotes epidémicos de triquinosis (7), la enfermedad tiene una prevalencia de 2 a $5 \%$ y constituye un importante problema de salud pública $(8,9)$. Por lo que se refiere a Bolivia, hasta 1993 se consideraba que la infección no existía en el país.

Recién en esa fecha, Bjorland et al. (10) utilizaron el ELISA para demostrar por primera vez una seroprevalencia de $11,2 \%$ de los anticuerpos contra T. spiralis en cerdos de 10 comunidades rurales del Altiplano. Sin embargo, la crianza de cerdos en el Altiplano es menos importante, en un sentido epidemiológico, que en los departamentos de Chuquisaca y Santa Cruz, donde se ubican la mayoría de los cerdos (59,9\%). Otros investigadores repitieron el estudio en 1327 cerdos faenados en los mataderos de tres centros urbanos de los departamentos de Monteagudo, Vallegrande y Santa Cruz. Utilizaron el ELISA y encontraron seroprevalencias de 12,4, 17,1 y 10,2 , respectivamente (11). Tomando en cuenta la zona de procedencia, se detectaron anticuerpos contra T. spiralis $^{6}$ en 14 de 80 cerdos $(17,5 \%)$ de la provincia Cordillera del departamento de Santa Cruz. Aunque no existe información sobre la presencia de las diferentes especies del género Trichinella en Bolivia, podrían encontrarse T. spiralis, por su carácter cosmopolita, y el fenotipo T5, por las características climáticas del área geográfica donde se efectuó el presente estudio (12).

El objetivo de esta investigación fue determinar la seroprevalencia de anticuerpos contra T. spiralis en individuos aparentemente sanos que residían en el área rural de la provincia Cordillera, Departamento de Santa Cruz. La provincia está situada $250 \mathrm{~km}$ al sur de la ciudad de Santa Cruz, en el sudeste de Bolivia; tiene una superficie total de $86245 \mathrm{~km}^{2}$ (7,84\% de todo el territorio

\footnotetext{
6 Méndez Cadima GJ. Detección de anticuerpos contra T. spiralis mediante la prueba ELISA en sueros de porcinos (en mataderos de Santa Cruz de la Sierra). Tesis de grado de Médico Veterinario Zootecnista. Santa Cruz de la Sierra, 1993.
}

boliviano), con alturas entre $389 \mathrm{y}$ $1203 \mathrm{~m}$ sobre el nivel del mar, y un clima que varía de subhúmedo a seco con una temperatura promedio anual de $29{ }^{\circ} \mathrm{C}$. La población es de 55675 habitantes (13) y aproximadamente $30 \%$ del total pertenece al grupo étnico guaraní. La ciudad principal es Camiri, con cerca de 33000 habitantes. La población rural practica formas de economía natural de subsistencia, tales como la agricultura y la crianza de animales, sobre todo ganado porcino $\mathrm{y}$ bovino. Habitualmente, los animales viven en libertad alrededor de la vivienda y se sacrifican en forma clandestina o domiciliaria. El régimen de alimentación de la población tiene como base fundamental el maíz, el arroz, las habas y la papa.

Para la muestra del estudio se seleccionaron aleatoriamente, utilizando el criterio de muestreo estratificado por sexo, 234 personas (125 mujeres y 109 hombres) de la zona rural de la provincia Cordillera. Para la distribución de sexos se usó como base la de toda la población. El tamaño de la muestra se determinó con el paquete Epi Info 6.0 y se estimó una tasa de prevalencia de anticuerpos contra T. spiralis de $4 \%$, con un nivel de confianza de 95\% (14).

Las actividades se realizaron durante el período de octubre a noviembre de 1996 y se iniciaron con una reunión con los pobladores seleccionados para explicarles el objetivo del estudio y sus procedimientos. A continuación se obtuvo una muestra de $5 \mathrm{~mL}$ de sangre venosa de cada individuo. Cuando se tomó la muestra de sangre de menores de edad, se les explicaron a los padres el propósito y los procedimientos del estudio y se obtuvo su consentimiento. Las muestras de sangre se centrifugaron y los sueros resultantes se almacenaron a una temperatura de $-20{ }^{\circ} \mathrm{C}$ para ser transportados a Italia conservados en hielo seco. Allí, los sueros fueron sometidos a prueba con el paquete Anti-Trichinella Serology Kit (LMD Laboratories, Inc., Carlsbad, California), utilizándose un ELISA preparado con antígeno excretor-secretor de T. spiralis. La prueba exacta de Fisher se utilizó para evaluar la significación estadística de las diferencias observadas.
Las pruebas permitieron detectar anticuerpos contra $T$. spiralis en siete de las 234 muestras de suero examinadas (3\%) (cuadro 1). Aunque las mujeres tuvieron una prevalencia de anticuerpos más baja que los hombres, la diferencia no fue estadísticamente significativa $(P=0,26)$. Las dos mujeres con resultados positivos tenían 36 y 40 años de edad; entre los varones, había tres niños de 7, 10 y 11 años de edad, un joven de 17 años y un adulto de 54 años. Dado el pequeño número de casos positivos observados, no fue posible analizar los datos por grupos de edad y lugar de procedencia. Tampoco se pudo disponer de las historias clínicas de los sujetos positivos.

Los resultados obtenidos documentan por primera vez la existencia de la infección por el gusano triquina en la población humana de Bolivia. Estos datos coinciden con las tasas de prevalencia observadas en otros países de América del Sur (1, 7-9). Aunque se desconoce si se dispone de información actual sobre casos de triquinosis humana en Bolivia, o sobre casos posibles o sospechosos identificados en el área del estudio, debe tenerse en cuenta que la mayoría de las infecciones humanas son subclínicas y que la intensidad del cuadro clínico está relacionada directamente con la cantidad de larvas ingeridas. La prevalencia relativamente baja de anticuerpos contra T. spiralis encontrada en la población humana estudiada puede explicarse

CUADRO 1. Prevalencia de anticuerpos contra Trichinella spiralis en la población humana del área rural de la provincia Cordillera, Departamento de Santa Cruz, Bolivia, 1996

\begin{tabular}{lccc}
\hline & \multicolumn{3}{c}{$\begin{array}{c}\text { Anticuerpos contra } \\
\text { T. spiralis }\end{array}$} \\
\cline { 2 - 4 } & & \multicolumn{2}{c}{ Positivos } \\
\cline { 2 - 4 } Sujetos & Estudiados & No. & $\%$ \\
\hline Mujeres & 125 & 2 & 1,6 \\
Varones & 109 & 5 & 4,6 \\
Total & 234 & 7 & 3,0 \\
\hline
\end{tabular}


por la costumbre de comer la carne bien cocida. La cocción a una temperatura de $\geq 77^{\circ} \mathrm{C}$ destruye las larvas y es la medida más eficaz para prevenir la triquinosis humana (15). Esta primera demostración de la infección de seres humanos por el gusano triquina en Bolivia, tras la comprobación de la presencia de triquinosis en el ganado porcino (10), sugiere la necesidad de fortalecer la vigilancia sanitaria en los mataderos municipales, impedir la faena clandestina de animales $y$, sobre todo, lograr que los productores y pobladores tomen conciencia de los peligros de esta zoonosis por medio de una educación sanitaria adecuada.

Agradecimiento. Mario Lagrava, Director Nacional de Epidemiología, Julio Méndez Saucedo, Director de la
Secretaría Regional de Salud de Santa Cruz, y Tarcisio Ciabatti, Coordinador del Convenio de Salud entre el Vicariato Apostólico de Cuevo y la Secretaría Nacional de Salud, colaboraron y facilitaron el trabajo de los investigadores. El equipo de trabajo en el campo $\mathrm{y}$, muy especialmente, Jorge Changaray, Nicolasa Callejas y Gilberto Acha brindaron su valiosa ayuda para recolectar las muestras.

\section{REFERENCIAS}

1. Acha PN, Szyfres B. Triquinelosis. Zoonosis y enfermedades transmisibles comunes al hombre y los animales. 3a. ed. Washington, DC: Organización Panamericana de la Salud; 1997:865-879. (Publicación científica 503).

2. Pozio E, La Rosa G, Murrell KD, Lichtenfels JR. Taxonomic revision of the genus Trichinella. J Parasitol 1992;78(4):654-659.

3. Capo V, Despommier DD. Clinical aspects of infection with Trichinella spp. Clin Microbiol Rev 1996;9(1):47-54

4. Yepez-Mulia L, Ortega-Pierres MG. Aspectos actuales sobre el diagnóstico de la triquinelosis. Rev Latinoam Microbiol 1994;36(2):127-138.

5. Morakote N, Sukhavat K, Khamboonruang C, Siriprasert V, Suphawitayanukul S, Thamasonthi W. Persistence of IgG, IgM, and IgE antibodies in human trichinosis. Trop Med Parasitol 1992;43(3):167-169.

6. Mahannop P, Setasuban P, Morakote N, Tapchaisri P, Chaicumpa W. Immunodiagnosis of human trichinellosis and identification of specific antigen for Trichinella spiralis. Int J Parasitol 1995;25(1):87-94.
7. Venturiello SM, Caminoa RA, Veneroni R, Costantino SN, Giambartolomei GH, Ledesma M, Scandurra N. Aspectos serológicos, clínicos y epidemiológicos de un brote de triquinosis en Azul, provincia de Buenos Aires. Medicina (Buenos Aires) 1993;53(1):1-5.

8. Zamorano CG, Contreras MC, Sánchez A, Bahamondes MA, Sandoval L. Estudio seroepidemiológico de la hidatidosis y triquinosis humana, mediante la reacción de hemaglutinación indirecta, en la Comuna de San Juan de la Costa. Osorno, X Región, Chile. 1990-1991. Bol Chil Parasitol 1991;46(3-4):82-84.

9. López R, Muñoz C, Nazar C, Rojas A, Schenone H. Prevalencia actual de la triquinosis en Santiago, Chile (1992); estudio en 500 cadáveres. Bol Chil Parasitol 1992;47(3-4):86-87.

10. Bjorland J, Brown D, Gamble HR, McAuley JB. Trichinella spiralis infection in pigs in the Bolivian Altiplano. Vet Parasitol 1993;47(3-4): 349-354.

11. Brown DF, Mendez Prado GA, Quiroga JL, Stagg DA, Mendez Cadima GJ, Sanchez Mendez LH, et al. Trichinella spiralis infection in pigs in eastern Bolivia. Trop Anim Health Prod 1996;28(2):137-142.

12. Pozio E, La Rosa G, Rossi P, Murrel KD. Biological characterization of Trichinella isolates from various hosts and geographical regions. J Parasitol 1992;78(4):647-653.

13. Bolivia, Instituto Nacional de Estadística. Censo nacional de población y vivienda, 1992. La Paz: INE; 1992

14. Epi Info, Version 6.0 [word processing, database and statistics program for epidemiology on microcomputers]. Atlanta, GA: United States of America, Centers for Disease Control and Prevention; 1994.

15. McAuley JB, Michelson MK, Schantz PM. Trichinosis surveillance, United States, 19871990. MMWR CDC Surveill Summ 1991;40 (SS-3):35-42.

Recibido el 1 de diciembre de 1997 y aceptado para publicación, tras revisión, el 21 de diciembre de 1998.
ABSTRACT

\section{Seroprevalence of antibodies to Trichinella spiralis among rural residents of Cordillera province, Bolivia}

A seroepidemiological study was conducted to determine the prevalence of antibodies to Trichinella spiralis among rural residents of Cordillera province, Santa Cruz Department, Bolivia. Using the enzyme-linked immunosorbent assay (ELISA), 234 serum samples were examined, and antibodies were detected in seven of the samples $(3 \%)$. The results document for the first time the presence of human infestation with Trichinella in Bolivia and suggest the need to strengthen trichinelosis surveillance in the municipal slaughterhouses, to prevent the clandestine slaughter of animals, and particularly to ensure that residents and meat producers in the area become aware of the dangers of this zoonosis. 